\title{
Growth and development of Calanus helgolandicus reared in the laboratory
}

\author{
Catherine Rey-Rassat $^{1, *}$, Xabier Irigoien ${ }^{2, * *}$, Roger Harris $^{2}{ }^{,}$Robert Head $^{2}$, \\ François Carlotti ${ }^{3}$
}

${ }^{1}$ Université Pierre et Marie Curie (Paris VI), Station Zoologique, ESA 7076, CNRS/INSU, BP 28, 06230 Villefranche-sur-mer, France

${ }^{2}$ Plymouth Marine Laboratory, Prospect Place, Plymouth PL1 3DH, United Kingdom

${ }^{3}$ Laboratoire d'Océanographie Biologique, CNRS, Université Bordeaux 1, UMR 5805, 2 rue du Professeur Jolyet, 33120 Arcachon, France

\begin{abstract}
Two Calanus helgolandicus cohorts were reared under laboratory conditions (150 1 tanks) at $15^{\circ} \mathrm{C}$ with the dinoflagellate Prorocentrum micans as food, at high $\left(278 \mu \mathrm{C} \mathrm{C}^{-1}, \mathrm{Cohort} \mathrm{H}\right)$ and low concentrations (77.5 $\mu \mathrm{g} \mathrm{C}^{-1}$, Cohort L), respectively. The study focused on the copepodite stages and for each stage, development time, total and structural growth rates, ingestion rate and gross growth efficiency were estimated. The growth rate of each stage was estimated using 2 methods, the classical one (Method I) and a new method (Method II), which considers the initial weight of the 2 successive stages rather than their mean weights. The initial weight corresponds to that estimated at the day $\left(t_{\text {ini }}\right)$ when $50 \%$ of the individuals in the cohort entered the stage. Using the new method, the increase in lipid deposition through copepodite stages (increase of the C:N ratio from 4.3 up to 4.7 and 6.9 in Cohorts $\mathrm{L}$ and $\mathrm{H}$, respectively) and the effect of food concentration on the growth rate from early $\mathrm{CI}$ to $\mathrm{CV}$ are clearly shown in the values of the growth rates (the CV growth rate in terms of carbon was $0.063 \mathrm{~d}^{-1}$ in Cohort $\mathrm{L}$ and $0.115 \mathrm{~d}^{-1}$ in Cohort $\mathrm{H}$ ). Both of these features are not apparent for the key stage CV when using the classical method $\left(0.041 \mathrm{~d}^{-1}\right.$ in Cohort L and $0.035 \mathrm{~d}^{-1}$ in Cohort $\mathrm{H}$ ). Female weight increase after moulting, by up to $\sim 60 \%$ in Cohort $\mathrm{L}$ and $\sim 40 \%$ in Cohort $\mathrm{H}$, is also demonstrated by the new method. Using Method II on field data is however limited to some specific cases in which the cohort development is synchronous; this might be particularly the case for some large copepods. Food supply influences the development time of stages CIV and CV, and differences are also found in the development time of each stage indicating a non-isochronal development. Food concentration also influences the gross growth efficiency (GGE) of all copepodite stages, with significantly higher GGE at the low food concentration. GGE varies with stage, mostly at low food concentration (for GGE in terms of carbon: 0.135 to 0.502 in Cohort L and 0.147 to 0.308 in Cohort H). Finally, we propose an index that can be used to indicate the position of an individual within its stage.
\end{abstract}

KEY WORDS: Calanus helgolandicus - Copepodite - Growth rate · Development · Ingestion · Efficiency $\cdot$ Food concentration $\cdot$ Method Resale or republication not permitted without written consent of the publisher

\section{INTRODUCTION}

In marine ecosystems, copepods are a key component of the zooplankton community and an important

\footnotetext{
*E-mail: catherinerey@aol.com or rey@obs-vlfr.fr

${ }^{* *}$ Present address: AZTI, Herrera Kaia portualdea z/g, 20110

Pasaia (Gipuzkoa), Spain
}

part of the diet of larval fish. The growth rate of each copepodite stage is frequently determined to calculate the production of a population (McLaren et al. 1989, Peterson \& Hutchings 1995, Hopcroft et al. 1998a, Escribano \& McLaren 1999). To explain the variability observed in the field among growth rates measured on different dates or in different areas, the relationship between growth rates and environmental variables, 
e.g. temperature, food concentration, food quality, is often investigated (Peterson et al. 1991, Hopcroft et al. 1998b, Richardson \& Verheye 1998, 1999, Calbet et al. 2000). A common method to calculate the growth rate of 1 stage is based on an assumption of exponential growth and on the determination of 3 different parameters, namely, the duration of the stage, its weight and that of the next stage. Many laboratory and field studies have reported the influence of stage duration on calculation of growth rate (Burkill \& Kendall 1982, Landry 1983, Corkett 1984, Miller et al. 1984, Kimmerer \& McKinnon 1987, Peterson \& Painting 1990, Klein Breteler et al. 1994, Jellison et al. 1995, Shreeve et al. 1998), which contrasts with the small number of studies addressing the influence of the weight determination on this calculation (McLaren \& Leonard 1995, McKinnon 1996, Shreeve \& Ward 1998). Several mathematical models coupling growth and development have pointed out the contribution of growth within stage to population production (Carlotti \& Sciandra 1989, Carlotti \& Nival 1992a, Miller \& Tande 1993). These models showed that the growth curve built from averaged weights within stage did not represent the optimal growth curve due to laggards (Carlotti \& Sciandra 1989, their Fig. 4, Carlotti \& Nival 1992a, their Fig. 8). Thus, the estimation of growth greatly depends on the weight used for the calculation, hence on the sampling strategy to obtain these values.

The objective of this study was to compare 2 methods of growth rate calculation in the particular case of a synchronous cohort development: one using weight increase between stages, the other weight increase within stage. This allowed us to demonstrate how the use of the classical method can mask some important results such as the influence of the food quantity on its measurement. The analysis is based on experimental data obtained on 2 cohorts of the copepod Calanus helgolandicus, one reared with a low algal supply and the other with a high algal supply. The accuracy of our data also allowed us to estimate the growth occurring in the somatic and reproductive tissues of the females, just after moulting, which has rarely been reported in the literature (McKinnon 1996, Hirst \& McKinnon 2002).

\section{MATERIALS AND METHODS}

Experimental set-up. Two cohorts of Calanus helgolandicus were isolated in June 1998, the second one $20 \mathrm{~d}$ after the first one. According to the results of Rey et al. (2001), the fact that both cohorts did not originate from the same spawning event does not have a significant effect on subsequent growth. To start a cohort, females collected from Stn L4 $\left(50^{\circ} 15^{\prime} \mathrm{N}, 4^{\circ} 13^{\prime} \mathrm{W}\right)$, approximately $10 \mathrm{~km}$ off Plymouth, western English Channel, were placed in several 2.51 Plexiglas cylinders with a $400 \mu \mathrm{m}$ mesh false bottom, suspended in $4 \mathrm{l}$ beakers filled with $0.8 \mu \mathrm{m}$ filtered seawater. After $12 \mathrm{~h}$, 5000 eggs were transferred into two $15 \mathrm{l}$ glass beakers previously filled with filtered seawater and provided with a suspension of Prorocentrum micans at an algal concentration of $200 \mathrm{cell} \mathrm{ml}^{-1}$. From hatching to Stage CI, the food concentration was checked every $12 \mathrm{~h}$ and the amount of algae consumed by the population was replaced. Once the majority had reached copepodite stage CI, 3500 individuals were transferred to a $150 \mathrm{l}$ polyethylene tank filled with a suspension of P. micans.

The 2 cohorts were reared at 2 different Prorocentrum micans concentrations. The first cohort was reared at a high food level (initial concentration fixed at $180 \mathrm{cell} \mathrm{ml}^{-1}$, Cohort $\mathrm{H}$ ), whereas the other cohort was fed at a lower concentration ( 50 cell ml ${ }^{-1}$, Cohort L). Both cohorts were maintained at $15^{\circ} \mathrm{C}$. Every 2 or $3 \mathrm{~d}$, the debris from the bottom of both $150 \mathrm{l}$ tanks was siphoned off in order to remove dead animals, moults and faecal pellets that had accumulated. This also allowed 10 to $20 \%$ of the incubation medium to be renewed.

Condition of the medium. Once a day, a certain volume of the medium (1.1 l in Tank L and 0.71 in Tank H) was sampled just after the phytoplankton concentration was restored to its initial level. This sample was divided in 3, filtered onto ashed glass fibre filters (Whatman $\mathrm{GF} / \mathrm{F}$ ) and stored at $-25^{\circ} \mathrm{C}$ for later analyses. One filter was used to estimate the chlorophyll concentration with a fluorometer (Turner Design) and the 2 others, to estimate particulate organic carbon and nitrogen using a Carlo Erba Elemental Analyser (model NAI500). Every $12 \mathrm{~h}$ (at 09:00 and 21:00 h), the cell concentration of Tanks $\mathrm{H}$ and $\mathrm{L}$ was estimated with triplicate cell counts made with a Coulter Multisizer, fitted with a $100 \mu \mathrm{m}$ orifice tube, and the phytoplankton ingested by the copepods was replaced. The dinoflagellate Prorocentrum micans (26.6 $\mu \mathrm{m}$ equivalent spherical diameter) was grown in a $10 \mathrm{l}$ semichemostat at $15^{\circ} \mathrm{C}$ using f/2 medium (Guillard 1975) under a 12:12 h light:dark cycle. Cell carbon and nitrogen contents were measured from aliquots of predetermined cell concentration at different times during the study. The algal sample was filtered onto ashed glass fibre filters and stored at $-25^{\circ} \mathrm{C}$ for later analyses.

Development, length and weight measurements. The development of each cohort was followed by sampling approximately 30 living animals every day from the tank and preserving them in $4 \%$ borax-buffered formaldehyde for later analysis. Stage duration was estimated on cumulative frequencies of individuals using the Peterson \& Painting (1990) method without any 
data transformation. The initial time $t=0$ was defined as the time when $50 \%$ of eggs were spawned. The cephalothoracic length of the preserved animals was also measured.

Copepodites were sampled daily after a gentle but thorough mixing to estimate their carbon and nitrogen content. Unfortunately, due to technical problems, samples collected between Days 16 and 19 in Cohort $\mathrm{H}$ were lost. Individuals collected from a sample were grouped by stage, rinsed in filtered seawater and placed on a GF/F filter in order to absorb the water and immobilize them. Finally, they were transferred to an ashed aluminium cup and stored at $-25^{\circ} \mathrm{C}$ for later analysis with a Carbo-Erba Elemental Analyser. The number of individuals per sample was 20 for CI, 15 for CII, 10 for CIII, 5 for CIV, and 1 for CV and adults. The number of replicate samples per day for each stage varied but it was usually 2 or 3 .

Growth rates. One of the aims of this study was to determine the importance of the method of growth rate calculation in order to highlight the factors influencing growth rates. Therefore, 2 methods were used to calculate growth rate $(k)$, one of which is common in the literature (McLaren et al. 1989, Peterson et al. 1991, Peterson \& Hutchings 1995, Hopcroft et al. 1998b) and one that we developed in this study.

The first method (Method I) is:

$$
k_{i}=\ln \left(W_{i+1} / W_{i}\right) \times 1 / D_{i}
$$

where $W_{i}$ or $\left(W_{i+1}\right)$ is the mean weight of copepodite stage $i$ or $i+1(\mu \mathrm{gC})$, and $D_{i}$ is the duration of stage $i(\mathrm{~d})$.

With this method, values of weight correspond either to the mean weight (Harris \& Paffenhöfer 1976, Escribano \& McLaren 1999), or to an estimate based on an allometric relationship between length and weight (Klein Breteler et al. 1982, Fryd et al. 1991, Peterson et al. 1991). The objective of Method I is to represent the mean growth pattern of all the individuals of the cohort. However, some assumptions in this method can be criticized: (1) the growth rate of 2 successive stages can vary significantly. Therefore, the growth rate of stage (i) as it is calculated in Eq. (1), i.e. by taking into account mean weight characteristics of stages $(i)$ or $(i+1)$, does not precisely reflect the weight increment of this stage but the increase and growth between stages; and (2) another weakness of Method I comes from the fact that in theory, the mean weight of a stage in Eq. (1) should be equal to the mean weight measured on each individual of the cohort at the middle of the stage considered, but this measurement may be inappropriately measured in the field.

We have developed another method (Method II) to calculate growth rates of reared cohorts (see Table 1) because of the potential problems of Method I. It is based on the determination of the initial weight ( $\left.W_{\text {ini }}\right)$ of cohort individuals at the entry to a stage, which means the weight at the day $\left(t_{\text {ini }}\right)$ when $50 \%$ of individuals entered the stage. The growth rate of the stage $i$ is still calculated with Eq. (1), but the weights considered in this expression are the initial weights of the stages $i$ and $i+1$. To estimate $W_{\text {ini }}$ for the stage $i$, first the mean weights for each of the sampling days are calculated; second, an exponential curve must be fitted to the data; and third, $W_{\text {ini }}$ is calculated by using the equation established for the date $\left(t_{\text {ini }}\right)$. The growth rate found with this method obviously represents individuals that have rather high growth rates compared to those of all the cohort individuals because $W_{\text {ini }}$ characterizes the first $50 \%$ of the individuals ahead of the cohort development.

For this study, in the case of Stage CI, we have assumed that $W_{\text {ini }}$ was equal to that calculated in the experiments of Rey et al. (2001) because we could not determine $t_{\text {ini }}$ (as data were not available). This assumption is based on the fact that the conditions during naupliar development in both these studies were the same (except that the food concentration was even higher in the present study since food was provided twice a day and only once in Rey et al. 2001). We have also assumed that $W_{\text {ini }}$ of the CI was equal to the value obtained by Rey et al. (2001), since in this study the weight was estimated from individuals collected on the first day of their entrance to the stage. This approach was used because in our present study we did not estimate the weight of the $\mathrm{CI}$ at the beginning at this stage.

To have a precise estimate of the CV growth rate, we needed to modify Method II for this stage. Originally, the growth rate of CV calculated with Method II used the initial weights of the CV and of the females. However, the weight of the CV at the end of the stage was much higher than that of the females at the beginning of the stage. Therefore, we present a better approach for calculating the $\mathrm{CV}$ growth rate, by using its weight at the beginning and at the end of the stage. The exit weight of $\mathrm{CV}\left(W_{\text {fin }}\right)$ was calculated from the same equation that was used for estimating $W_{\text {ini }}$ but on the date at which $50 \%$ of the cohort individuals left the stage.

Wax ester contents and structural growth rates. The preserved copepods were also used to estimate the lipid content of Stages CIV, CV and adults by measuring the volume of their oil sac (for details see Rey et al. 1999). It is important to emphasize that the CIV and CV individuals used to estimate the lipid content were those sampled on the day of their respective mid-stage. The volume (in ml) was transformed into wax ester (in $\mathrm{gC}$ ) by (1) multiplying it by the density of $0.86 \mathrm{~g}$ $\mathrm{ml}^{-1}$ (Sargent \& Henderson 1986), (2) multiplying it by the ratio of the carbon content in wax ester of 0.78 
(from Table 2.3 of Sargent \& Henderson 1986), and (3) dividing it by 1.44, a conversion factor coming from the fact that the wax ester content estimated from the oil sac volume was found to be 1.44 higher than that estimated from a calibrated Iastroscan determination, in Miller et al. (1998, from their Fig. 6).

To calculate the structural growth rate, we estimated for each stage the fraction of the initial weight due to wax ester, which corresponds to the wax ester content on the date when $50 \%$ of the individuals in the cohort entered a stage $\left(W_{\mathrm{WE}, \text { ini }}\right)$. For Stages CI to CIII of both cohorts, we assumed that $W_{\mathrm{WE}, \text { ini }}$ was 0 since lipid deposition is known to start during CIII (Hygum et al. 2000). For both cohorts, exponential and linear equations were fitted to wax ester contents measured directly at the mid-stage of CIV and CV. Hygum et al. (2000) found that wax ester deposition from CIII to the end of CV was better represented by a linear model, especially in the case of a cohort reared with a low food supply. However, we decided to use the exponential equation for the estimation of the $W_{\mathrm{WE} \text {,ini }}$ of Stages CIV and CV at $t_{\text {ini }}$ of both these stages, and to use the linear equation to estimate the wax ester content at the end of Stage CV ( $W_{\mathrm{WE}, \text { fin }}$, i.e. when $50 \%$ of the individuals left the stage). This was done because we would have found negative values for the $W_{\mathrm{WE} \text {,ini }}$ of CIV if we had used the linear equation and because lipid increment appears to slow down especially during the second half of CV in Hygum et al. (2000).

The structural weight of each stage was determined from the initial weight (and final weight in the case of the $\mathrm{CV}$ ) expressed as total carbon minus the carbon contribution from wax ester. The structural growth rates were calculated using Method II applied to the structural weights.

Ingestion experiments and gross growth efficiency. The ingestion of each copepodite stage was estimated by collecting animals on the day when the first individuals of a new stage were found. In other words, this means that our ingestion rates have been estimated for the fastest-growing individuals. Groups of individuals (10 for CI and CII, 7 for CIII, 6 for CIV and 4 for CV and adults) were placed in glass bottles (1.5 1 for CI and CII and 2.51 for CIII to adult) filled with filtered seawater and provided with the same algal concentration as in the $150 \mathrm{l}$ tanks. Four replicates and 4 controls were placed on a rotating wheel for $24 \mathrm{~h}$. The cell concentration at the beginning and at the end of the experiments was measured using a Coulter Multisizer. Filtration and ingestion rates were calculated following Frost (1972). The gross growth efficiency (GGE) of a given stage was calculated by considering its growth rate determined using Method II divided by its specific ingestion rate (i.e. the ingestion rate divided by the initial weight).
Statistics. Lengths were compared using parametric $Z$-tests after testing for homogeneity of the variances, as were the log-transformed values of weights. ANOVA followed by Tukey tests (for multiple comparisons) were done on the log-transformed values of ingestion rate in order to compare values found for the different categories of stages of 1 cohort. Finally, the linear regressions found for each cohort between the logarithmic values of the ingestion rates versus the logarithm of the initial weights were analyzed using covariance analyses.

\section{RESULTS}

\section{Nutritional conditions}

The average chlorophyll concentration was $0.79 \mu \mathrm{g}$ chl a $\mathrm{l}^{-1}$ for Cohort L and $3.09 \mu \mathrm{g} \mathrm{chl} \mathrm{a}^{-1}$ for Cohort $\mathrm{H}$ (Fig. 1). Multiplying cell counts by the average content per Prorocentrum micans cell (2803 g C and 383 pg N), we found a mean carbon concentration of 77.5 and $278 \mu \mathrm{g} \mathrm{C}^{-1}$ for Cohorts L and $\mathrm{H}$, respectively. Particulate organic carbon and nitrogen concentrations (filled symbols in Fig. 1C-F), the values were higher than those calculated by considering the average carbon and nitrogen per cell (open symbols in Fig. 1C-F). This was due to an accumulation of detritus despite the cleaning process (e.g. broken fecal pellets), and it is assumed that this part of the particulate fraction was not used by the developing cohorts.

\section{Cohort analysis}

As expected, the duration of stages, estimated from the cumulative stage frequencies (Fig. 2), was the same from egg to CI for both cohorts because the food concentration only differed after Stage CI (Table 1). For Stages CII to $\mathrm{CV}$, the development was not isochronal: in both cohorts, the duration of CII and CIII (also the duration of the CIV in the case of Cohort $\mathrm{H}$ ) was similar, but the duration of $\mathrm{CV}$ was markedly longer than the others. The development times of Stages CIV and CV in Cohort L were longer than those in Cohorts H. Another important observation concerns the sex ratio found at the end of the development of both cohorts. The percentage of males was $15 \%$ in Cohort $\mathrm{H}$ whereas it was 0 in Cohort $\mathrm{L}$. Because of this lack of males, the females we found in our cultures were mostly unfertilized, at least during the first week of the adult appearance. The results presented in this paper on the weight, length and ingestion rates of females are those obtained from unfertilized females. 
Cohort L
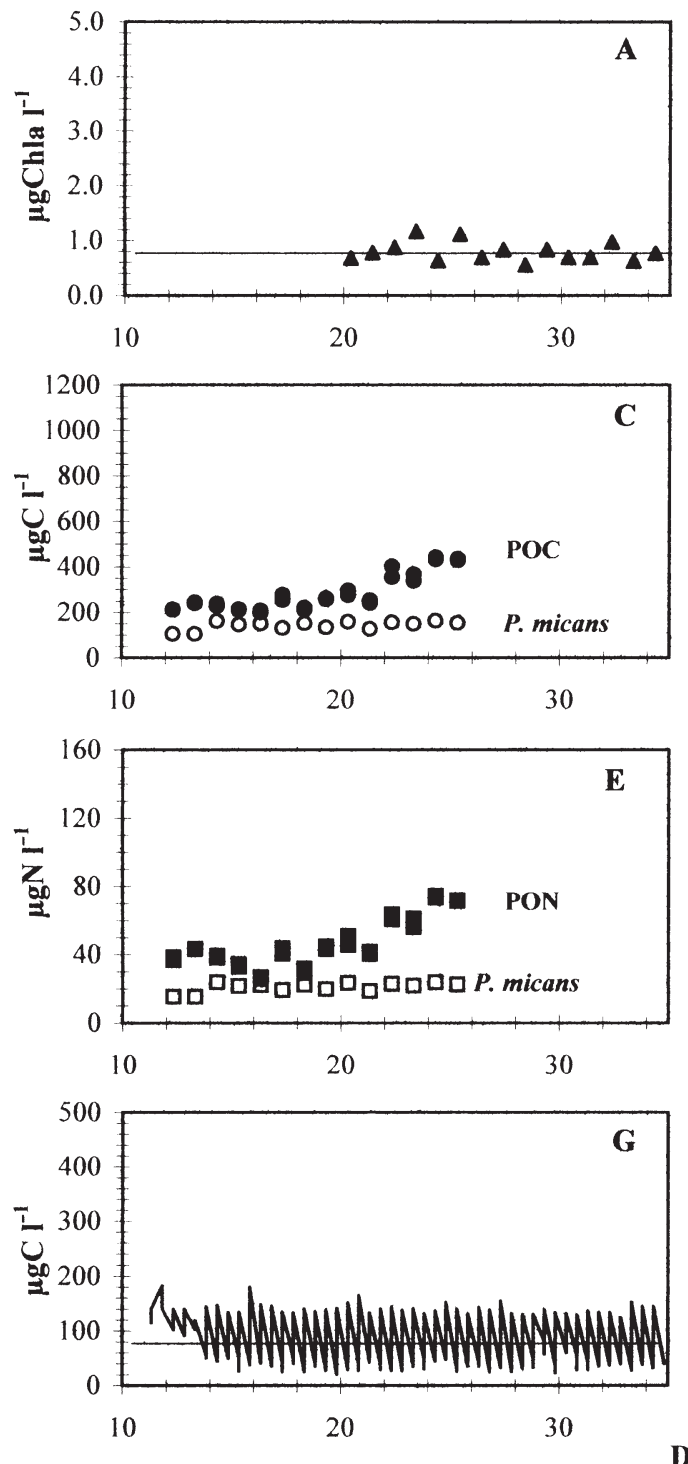
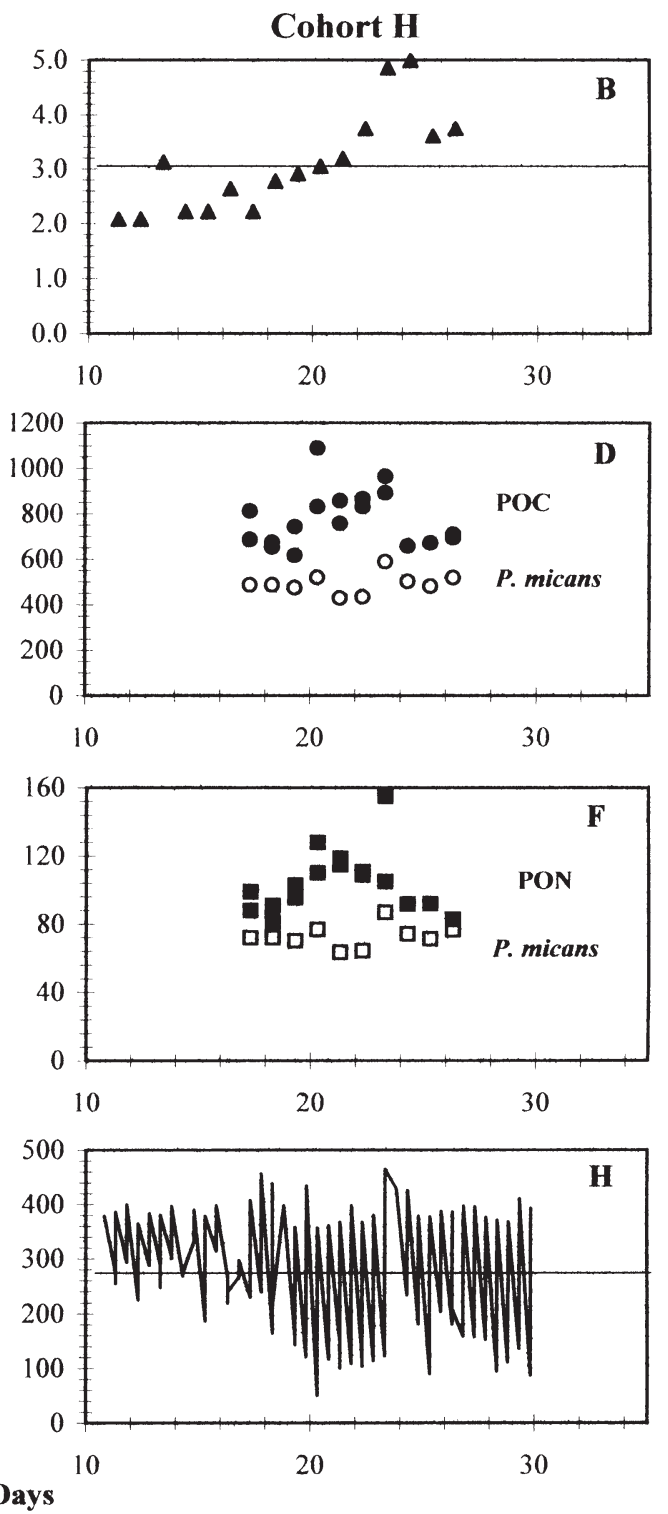

Fig. 1. Nutritional conditions in both tanks with the Cohorts L (low Prorocentrum micans concentration, left column) and H (high concentration, right column). The initial time $t=0$ was defined as the time when $50 \%$ of eggs were spawned. (A,B) are the chl $a$ concentrations. $(\mathrm{C}, \mathrm{D})$ and $(\mathrm{E}, \mathrm{F})$ are the particulate organic carbon and nitrogen concentration, respectively. The filled symbols indicate raw data and the open ones, the values estimated from the P. micans cell counts and the carbon content of the algal cell. $(\mathrm{G}, \mathrm{H})$ are the carbon concentrations estimated from each $12 \mathrm{~h}$ cell counts and the carbon content of the algal cell. The horizontal bars in $(A, B, G, H)$ indicate the mean value

\section{Weight measurement}

For the copepodite stages, carbon and nitrogen content increased both within stage and between successive stages (Fig. 3). We observed a certain overlap between the values for 2 successive stages within the same cohort (e.g. between the carbon and nitrogen content of Stages CIV and CV of Cohorts L and H). Growth, in terms of carbon or nitrogen, appears to follow an exponential rule within a stage, even if growth slows down in the case of $\mathrm{CV}$ in both cohorts (also CIV in the case of Cohort L). In the case of females, their initial weight was rather low compared to the late Stage $C V$, which suggests a significant catabolism during the final moulting process. We also observed an increase with time in the carbon content of these females. In terms of nitrogen, this increase was evident only for females of Cohort L. As expected, the mean weight increased exponentially with stage (Table 2). Values for stages of Cohort L were always 


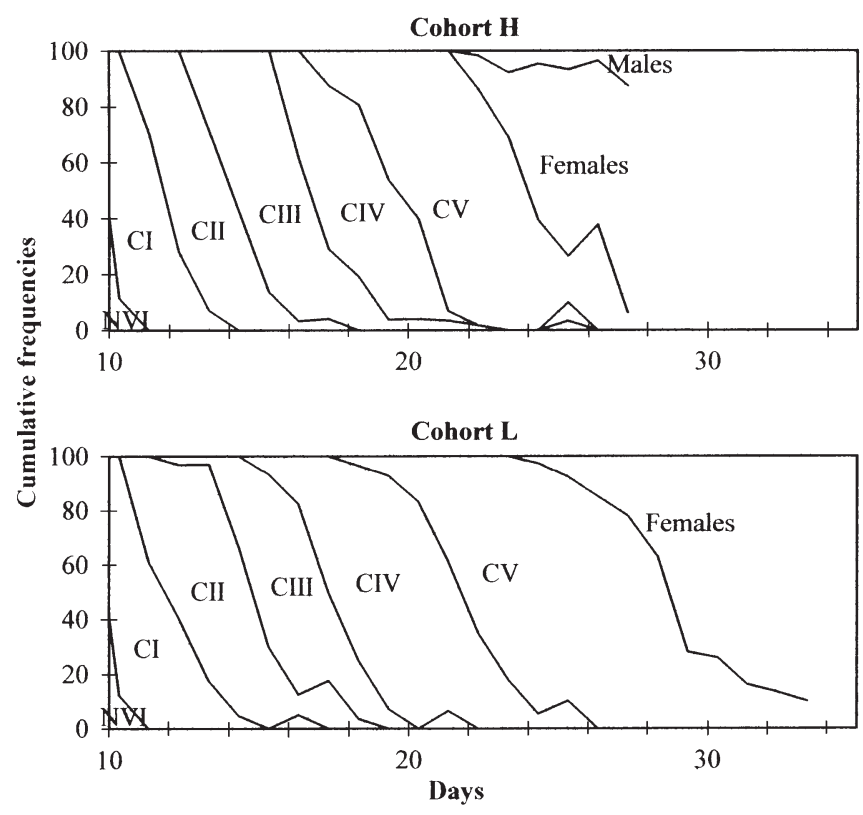

Fig. 2. Calanus helgolandicus. Cumulative frequency of individual number per copepodite stage of the Cohorts $\mathrm{L}$ and $\mathrm{H}$ $\left(15^{\circ} \mathrm{C}\right)$. Each cohort came from eggs spawned within a $12 \mathrm{~h}$ period and the initial time $t=0$ is defined as the time when $50 \%$ of eggs were spawned

lower than those of Cohort $\mathrm{H}$ (particularly for CV and females). The weight of males from Cohort $\mathrm{H}$ was measured on 1 day only, and on this date the mean weight was not different from that of females on the same day.
Table 1. Calanus helgolandicus. Duration of the copepodite stages (in days) for Cohorts $\mathrm{L}$ and $\mathrm{H}$

\begin{tabular}{|lccccc|}
\hline & Egg to CI & CII & CIII & CIV & CV \\
\hline Cohort L & 12.0 & 2.9 & 2.6 & 4.3 & 7.0 \\
Cohort H & 11.9 & 2.2 & 2.9 & 2.6 & 4.8 \\
\hline
\end{tabular}

\section{Growth rate}

Using Method I, we can see a general decrease in growth rate values throughout the stages but with a peak at Stage CIII (Table 3). Rates for Cohort L were usually lower than those for Cohort $\mathrm{H}$ although this was not true for CV. For each stage, growth rates calculated either from carbon or nitrogen weights were rather similar. After determining the initial weight $W_{\text {ini }}$ for each stage (Table 2), the values of growth rates found with Method II were compared to those found with Method I (Table 3). In both methods trends were similar: rates decreased from CIII to $\mathrm{CV}$ and rates for Cohort $\mathrm{L}$ were lower than those for Cohort $\mathrm{H}$. However, with Method II, the growth rates calculated from carbon weights of CIII were always higher than those estimated from nitrogen. Also, fluctuations between rates of Stages CI to CIII were smoothed with Method II, which certainly reflects a more realistic scenario. For Stages CIV and CV, rates found with Method II were usually higher than those with Method I, and differed by up to $232 \%$ in the case of CV at high

Table 2. Calanus helgolandicus. Mean and initial carbon $(\mathrm{C}$, in $\mu \mathrm{g} \mathrm{C})$ and nitrogen $(\mathrm{N}$, in $\mu \mathrm{g} \mathrm{N})$ content. Mean weights were calculated from all the data available for each copepodite and adult stages of Cohorts L and H. Initial weights were calculated from exponential equation at the date ( $t_{\text {ini, }}$ available from data of Table 1 ) when $50 \%$ of the individuals of the cohort entered each of the stages from CII to female (Method II). For the particular calculation of the CI weight see the text. The SD is indicated after the mean value, and the number of replicates are provided between parentheses. PF: probability that variances are equal (homoscedasticity); PZ: probability that the log-transformed values of the mean weight for 1 given stage are equal. The variances or the log-transformed values of the mean weights that are found significantly different (or not) at the $5 \%$ level are indicated by s (or ns)

\begin{tabular}{|c|c|c|c|c|c|c|c|c|c|c|c|c|c|c|}
\hline & & \multicolumn{2}{|c|}{$\mathrm{CI}$} & \multicolumn{2}{|c|}{ CII } & \multicolumn{2}{|c|}{ CIII } & \multicolumn{2}{|r|}{ CIV } & & $\mathrm{CV}$ & \multicolumn{2}{|c|}{ Female } & Male \\
\hline \multicolumn{15}{|c|}{ Mean weight } \\
\hline & Cohort L & \multicolumn{2}{|c|}{$2.21 \pm 0.17$} & \multicolumn{2}{|c|}{$4.12 \pm 0.95$} & \multicolumn{2}{|c|}{$8.37 \pm 2.10$} & \multicolumn{2}{|c|}{$26.20 \pm 7.99$} & \multicolumn{2}{|c|}{$46.55 \pm 14.08$} & \multicolumn{2}{|c|}{$61.8 \pm 19.0$} & - \\
\hline & Cohort $\mathrm{H}$ & \multicolumn{2}{|c|}{$2.37 \pm 0.28$} & \multicolumn{2}{|c|}{$4.82 \pm 0.94$} & \multicolumn{2}{|c|}{$10.40 \pm 1.81$} & \multicolumn{2}{|c|}{$42.03 \pm 18.40$} & \multicolumn{2}{|c|}{$97.28 \pm 34.7$} & \multicolumn{2}{|c|}{$114.8 \pm 22.3$} & $114.8 \pm 20.5$ \\
\hline & $\mathrm{PF}$ & $\mathrm{ns}$ & 0.81 & ns & 0.33 & $\mathrm{~ns}$ & 0.10 & ns & 0.90 & ns & 0.97 & $\mathrm{~s}$ & 0.00 & \\
\hline & PZ & ns & 0.28 & ns & 0.12 & $\mathrm{~s}$ & 0.03 & ns & 0.06 & $\mathrm{~s}$ & 0.00 & $\mathrm{~s}$ & 0.00 & - \\
\hline \multirow[t]{4}{*}{$\mathrm{N}$} & Cohort L & \multirow{2}{*}{\multicolumn{2}{|c|}{$\begin{array}{l}0.54 \pm 0.06 \\
0.58 \pm 0.07\end{array}$}} & \multirow{2}{*}{\multicolumn{2}{|c|}{$\begin{array}{l}0.98 \pm 0.21(8) \\
1.19 \pm 0.25\end{array}$}} & \multirow{2}{*}{\multicolumn{2}{|c|}{$2.02 \pm 0.43$}} & \multirow{2}{*}{\multicolumn{2}{|c|}{$5.74 \pm 1.53(16)$}} & \multirow{2}{*}{\multicolumn{2}{|c|}{$10.11 \pm 2.75$}} & \multicolumn{2}{|c|}{$14.7 \pm 4.2$} & - \\
\hline & Cohort $\mathrm{H}$ & & & & & & & & & & & 21.7 & $+3.9(86)$ & $19.5 \pm 2.0$ \\
\hline & $\mathrm{PF}$ & ns & 0.56 & ns & 0.43 & ns & 0.11 & ns & 0.83 & ns & 0.22 & $\mathrm{~s}$ & 0.00 & \\
\hline & $\mathrm{PZ}$ & ns & 0.33 & $\mathrm{~ns}$ & 0.06 & $\mathrm{~s}$ & 0.02 & ns & 0.14 & $\mathrm{~s}$ & 0.00 & $\mathrm{~s}$ & 0.00 & - \\
\hline \multicolumn{15}{|c|}{ Initial weight } \\
\hline & Cohort L & \multicolumn{2}{|c|}{1.75} & \multicolumn{2}{|c|}{3.60} & \multicolumn{2}{|c|}{7.54} & \multicolumn{2}{|r|}{18.28} & & 36.59 & \multicolumn{2}{|c|}{58.40} & \\
\hline & Cohort $\mathrm{H}$ & \multicolumn{2}{|c|}{1.75} & & 16 & & 38 & & 28.86 & & 65.21 & & & - \\
\hline $\mathrm{N}$ & Cohort L & & 40 & & 85 & & 84 & & 4.15 & & 8.33 & & & \\
\hline & Cohort H & & 40 & & 06 & & 30 & & 5.90 & & 13.03 & & & \\
\hline
\end{tabular}


Cohort L
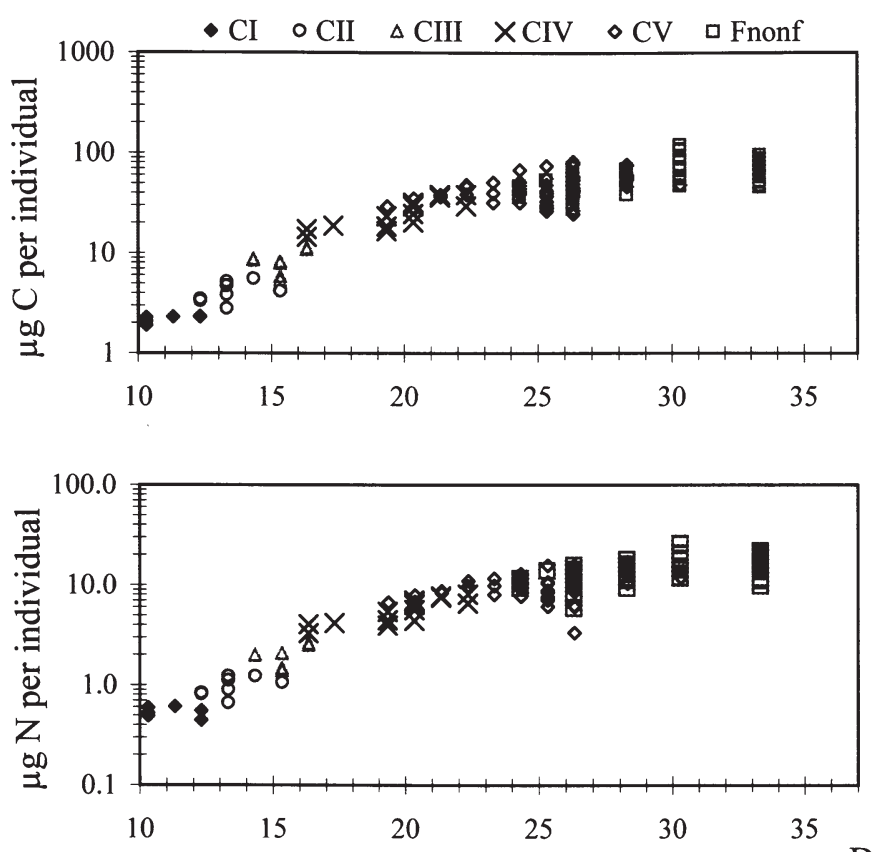

Cohort H

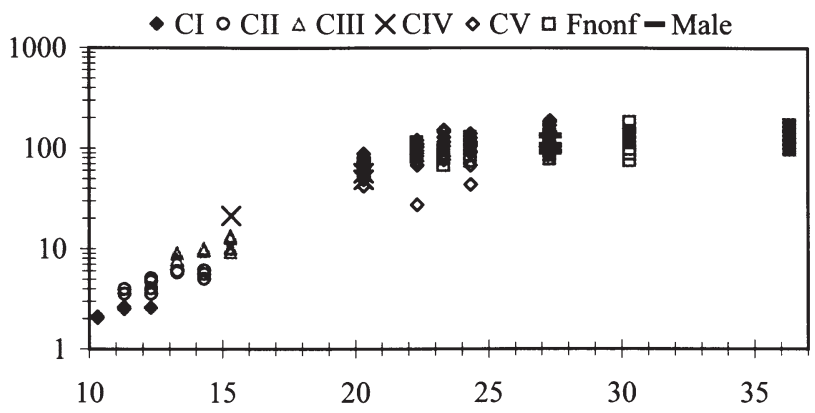

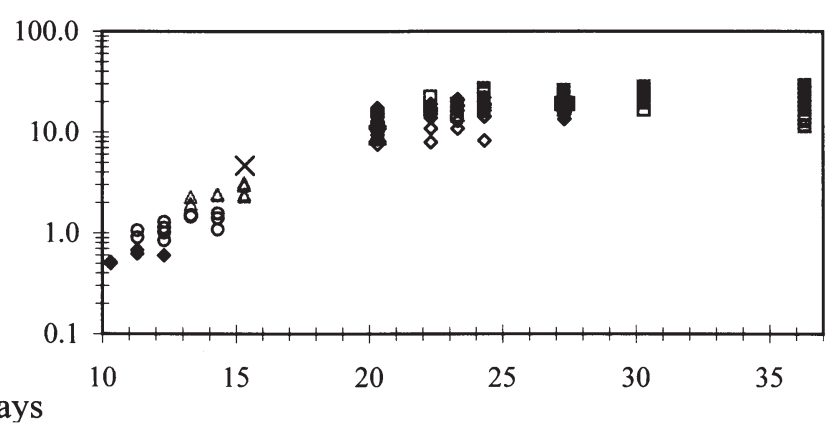

Fig. 3. Calanus helgolandicus. Carbon and nitrogen content per individual for copepodite and adult stages from the Cohorts L (low food concentration) and $\mathrm{H}$ (high concentration). The day $t=0$ is defined as the time when $50 \%$ of eggs were spawned

food concentration. This underlines the importance of the choice of method in the growth rate calculation, even if differences between both methods are lower when the growth rates of the different stages are pooled (Table 3).

In the case of growth rates found with Method II for CIII and CIV of Cohort $\mathrm{H}$, the estimation was less accurate due to a gap in the weight measurements in both these cases (Fig. 3). This is particularly true for Stage CIV, for which the $W_{\text {ini }}$ was calculated from an exponential equation fitted on 2 sampling days only (and 3 weight measurements originally). For Stage CIII, things were different since it was the weight at the end of the stage that was not well sampled. In other words, the equation required for the determination of the $W_{\text {ini }}$ was fitted mostly to weight data found at the start of the stage, which means that our value of $W_{\text {ini }}$ was undoubtedly accurate enough to provide an adequate estimate of the CIII growth rate.

Table 3. Calanus helgolandicus. Specific carbon (total carbon: $\mathrm{C}_{i}$ structural carbon: $\mathrm{C}$-struct) and nitrogen $(\mathrm{N})$ growth rates $\left(\mathrm{d}^{-1}\right)$ calculated by using Methods I and II. Method I considers mean weight, whereas Method II considers initial weight. For the growth rates of the CV, Method II also uses final weight (cf. text)

\begin{tabular}{|c|c|c|c|c|c|c|c|c|c|c|}
\hline & & & CI & CII & CIII & CIV & $\mathrm{CV}$ & $\mathrm{CI}-\mathrm{CV}$ & CI-CIII & $\mathrm{CIV}-\mathrm{CV}$ \\
\hline \multirow[t]{4}{*}{ Method I } & \multirow[t]{2}{*}{$\mathrm{C}$} & Cohort L & 0.228 & 0.246 & 0.440 & 0.133 & 0.041 & 0.171 & 0.302 & 0.076 \\
\hline & & Cohort H & 0.273 & 0.350 & 0.474 & 0.321 & 0.035 & 0.256 & 0.371 & 0.135 \\
\hline & \multirow[t]{2}{*}{$\mathrm{N}$} & Cohort L & 0.219 & 0.251 & 0.403 & 0.131 & 0.054 & 0.170 & 0.289 & 0.084 \\
\hline & & Cohort H & 0.277 & 0.335 & 0.386 & 0.258 & 0.073 & 0.239 & 0.335 & 0.138 \\
\hline \multirow[t]{4}{*}{ Method II } & \multirow[t]{2}{*}{$\mathrm{C}$} & Cohort L & 0.263 & 0.257 & 0.341 & 0.161 & 0.063 & 0.178 & 0.286 & 0.100 \\
\hline & & Cohort H & 0.332 & 0.370 & 0.381 & 0.312 & 0.115 & 0.275 & 0.362 & 0.184 \\
\hline & \multirow[t]{2}{*}{$\mathrm{N}$} & Cohort L & 0.271 & 0.270 & 0.313 & 0.161 & 0.053 & 0.174 & 0.284 & 0.094 \\
\hline & & Cohort H & 0.370 & 0.354 & 0.320 & 0.303 & 0.049 & 0.245 & 0.346 & 0.138 \\
\hline \multirow{2}{*}{ Method II } & \multirow[t]{2}{*}{ C-struct } & Cohort L & 0.263 & 0.257 & 0.263 & 0.152 & 0.027 & 0.153 & 0.261 & 0.075 \\
\hline & & Cohort H & 0.332 & 0.370 & 0.324 & 0.295 & 0.043 & 0.238 & 0.340 & 0.132 \\
\hline
\end{tabular}


The growth rate of the females was calculated in a simple way by fitting an exponential curve to the whole data set of the female weights (Fig. 3). In fact, the growth seems to be linear rather than exponential. However, we preferred to use the exponential fitting in order to obtain female growth rates in the same units as those for the copepodite growth rates. The female growth rates from Cohort $\mathrm{H}$ (from carbon and nitrogen data: 0.044 and $0.030 \mathrm{~d}^{-1}$ ) were lower than those from Cohort L (from carbon and nitrogen data: 0.057 and $0.053 \mathrm{~d}^{-1}$ ) but rates were probably underestimated since the recruitment of the females was not synchronous. The last females sampled to determine their
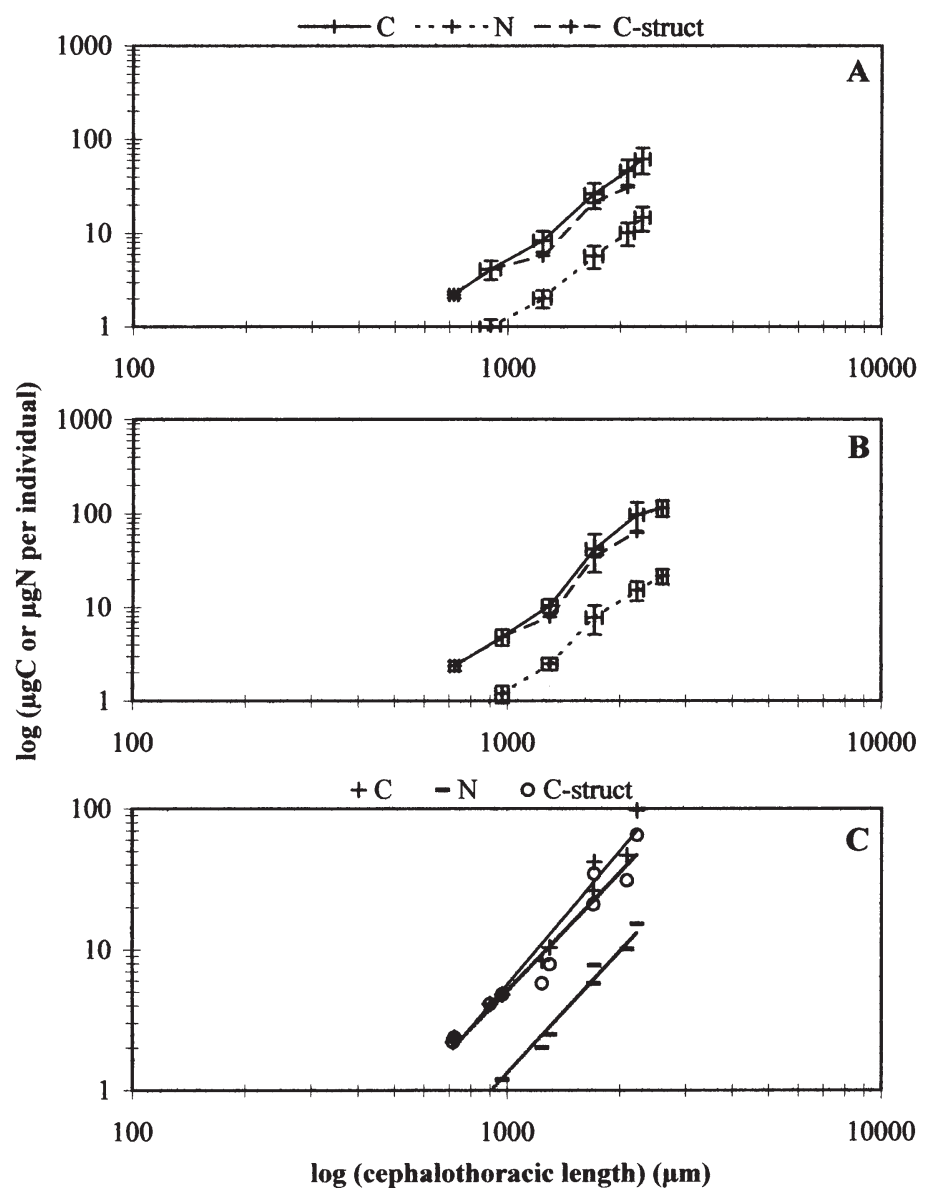

Fig. 4. Calanus helgolandicus. Relationships between the logarithm of the length $(\mu \mathrm{m})$ and the logarithm of the mean weight in terms of total carbon (C), structural carbon (C-struct), nitrogen (N) for Cohort L (A) and Cohort H (B). Vertical bars represent SD. (C) Allometric relationships fitted to mean weight of CI to CV from both cohorts. Data on adults were not considered because structural carbon weight was not available for them. Allometric relationships: Total body mass of carbon $=1.9526 \times 10^{-9} \times$ Length $^{3.1538}\left(\mathrm{R}^{2}=0.97\right)$; Structural body mass of carbon $=2.1329 \times 10^{-8} \times$ Length $^{2.7925}$ $\left(\mathrm{R}^{2}=0.95\right)$; Total body mass of nitrogen $=2.9874 \times 10^{-9} \times$ Length ${ }^{2.8827}\left(R^{2}=0.99\right)$ weight could have been either old females that moulted earlier or new females that had just entered the stage.

\section{Wax ester content and structural growth rate}

The increase in wax ester content between midstages CIV and CV was higher for Cohort $\mathrm{H}$ (mean $\pm \mathrm{SD}$ : $7.52 \pm 5.22 \mu \mathrm{g} \mathrm{C}$ for CIV and $32.28 \pm 16.46 \mu \mathrm{g} \mathrm{C}$ for $\mathrm{CV}$ ) than for Cohort L $(5.15 \pm 4.45$ for CIV and $15.63 \pm 15.87$ for $\mathrm{CV}$ ). The exponential and linear equations that relate the 2 mean values found for the CIV and CV in both cohorts were estimated:

For Cohort L:

Wax ester $=0.1085 \times \exp (0.1966 \times$ time $)$

Wax ester $=1.8559 \times$ time -31.296

For Cohort H:

Wax ester $=0.0056 \times \exp (0.3927 \times$ time $)$

Wax ester $=6.6745 \times$ time -114.79

The $W_{\mathrm{WE} \text {,ini }}$ of CIV and CV was estimated from the exponential equation of Cohorts $\mathrm{H}$ and $\mathrm{L}$ whereas the $W_{\mathrm{WE}, \text { fin }}$ of $\mathrm{CV}$ was estimated from the linear equation.

The structural growth rates of CIV and especially CV were much lower than the total growth rates (Table 3), which emphasizes the considerable amount of wax ester accumulated during these stages.

\section{Body size and allometric relationships}

The cephalothoracic length measurements (Fig. 4) indicated that, from $\mathrm{CII}$ to adult, copepods in Cohort $\mathrm{H}$ were always significantly larger than those in Cohort L ( $p$ always $<0.05$ ). The males, found only in Cohort $H$, were significantly smaller than the females. Allometric relationships between mean weights (in $\mu \mathrm{g} C$ or $\mu \mathrm{gN}$ ) and lengths (in $\mu \mathrm{m}$ ) were calculated from total and structural body mass of carbon and total body mass of nitrogen by taking into account data from both cohorts together (Fig. 4C).

\section{Ingestion and gross growth efficiency}

Absolute ingestion rates of both cohorts increased significantly through successive stages in terms of both carbon and nitrogen (Table 4, ANOVA) although specific ingestion rate declined with increasing copepod size (Fig. 5). Ingestion rate was significantly affected by Prorocentrum micans concentration, both in absolute terms (Table 4, ANCOVA - as indicated by the different intercepts) and on a weight-specific basis 

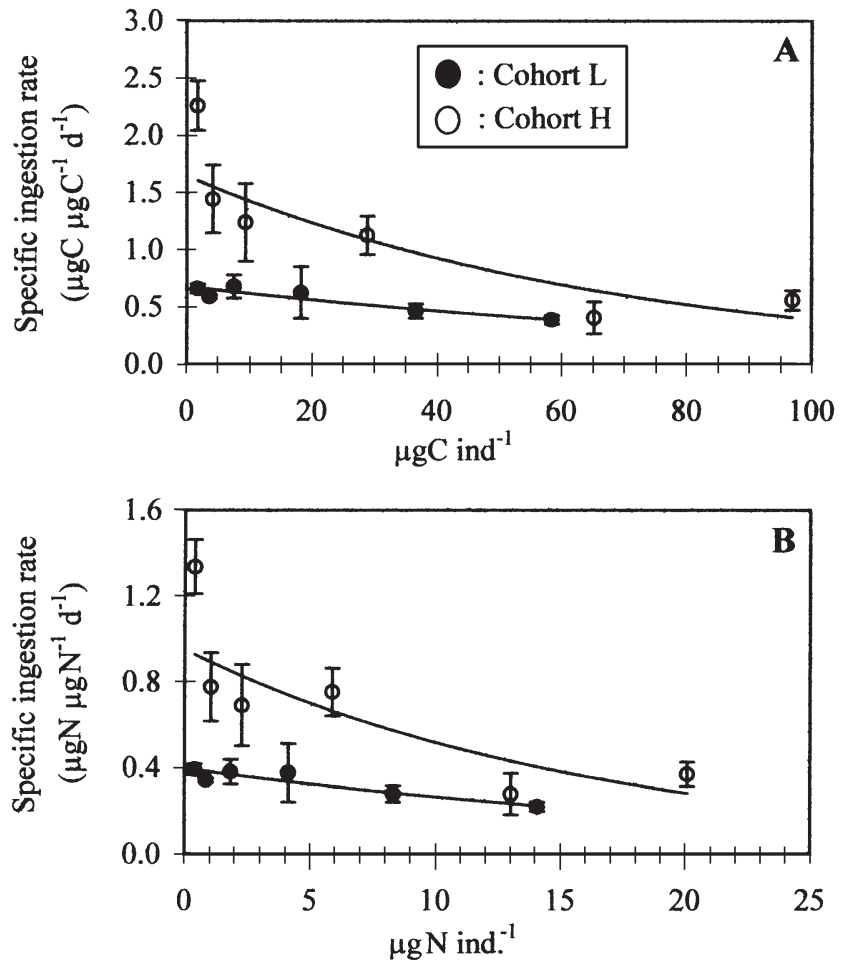

Fig. 5. Calanus helgolandicus. Specific ingestion rate (i.e. the ingestion rate divided by the initial weight) (A) in terms of carbon $\left(\mu \mathrm{gC} \mu \mathrm{gC}^{-1} \mathrm{~d}^{-1}\right)$ and (B) nitrogen $\left(\mu \mathrm{gN} \mu \mathrm{gN}^{-1} \mathrm{~d}^{-1}\right)$ versus the initial weight of each stage of Cohorts $\mathrm{L}$ and $\mathrm{H}$. Vertical bars represent SD. Exponential curves are fitted to the data of each cohort: For Cohort L: Specific ingestion rate $(C)=1.6480$ $\times \mathrm{e}^{(-0.0144) \times \text { Weight in C }}\left(\mathrm{R}^{2}=0.77\right)$; Specific ingesting rate $(\mathrm{N})=$ $0.3972 \times \mathrm{e}^{(-0.0403) \times \text { Weight in N }}\left(\mathrm{R}^{2}=0.89\right)$; for Cohort H: Specific ingestion rate $(C)=0.6799 \times \mathrm{e}^{(-0.0094) \times \text { Weight in C }}\left(\mathrm{R}^{2}=0.89\right)$; Specific ingestion rate $(\mathrm{N})=0.9509 \times \mathrm{e}^{(-0.0605) \times \text { Weight in } \mathrm{N}}\left(\mathrm{R}^{2}=0.71\right)$
(Fig. 5). From Stage CI to CIII, GGE values in terms of carbon $\left(\mathrm{GGE}_{\mathrm{C}}\right)$ or nitrogen $\left(\mathrm{GGE}_{\mathrm{N}}\right)$ were almost stable but significantly higher in Cohort L than $\mathrm{H}$ (Fig. 6). From Stage CIV to CV in Cohort L, GGE values decreased whereas they remained relatively stable in Cohort $\mathrm{H}$. We can also see that values of $\mathrm{GGE}_{\mathrm{C}}$ were generally lower than those of $\mathrm{GGE}_{\mathrm{N}}$.

\section{DISCUSSION}

\section{Methodology}

As Hopcroft et al. (1998b) stated: 'it is nonetheless frustrating that numerous studies purporting to explore "growth" actually report only stage specific development'. It is quite remarkable to see how many studies have been done comparing methods to estimate development time in contrast to the few checking the influence of the weight in Eq. (1) (as in 'Materials and methods', but see 'Introduction' for references).

In our study, we have used a new, more accurate approach to calculate the growth rate of the different copepodite stages in order to determine the influence of food quantity during growth. By using this approach we were able to characterize some important physiological phenomena, which would have been missed by using the classical method. First, Method II enabled the fluctuations found with Method I among rates of Stages CI to CIII to be smoothed, which corresponds certainly to a more realistic scenario. Second, from Stages CIII to CV, Method II estimated growth rates in terms of carbon, which were always higher than those in terms of nitrogen, reflecting the importance of lipid

Table 4. Calanus helgolandicus. Ingestion rate expressed in terms of carbon $\left(\mu \mathrm{g} C\right.$ ind.$\left.^{-1} \mathrm{~d}^{-1}\right)$ or nitrogen $\left(\mu \mathrm{gN}\right.$ ind.- $\left.\mathrm{d}^{-1}\right)$ of each copepodite and adult stage of the Cohorts L and H. Each mean value is calculated from 4 replicates and is followed by the SD. ANOVA followed by Tukey tests (for multiple comparisons) were done on the log-transformed values of ingestion rate in order to compare values found for the different categories of stages of 1 cohort. The linear regressions found for both cohorts between the logarithmic values of the ingestion rate and the initial weight of each stage were compared (slopes and the ordinate) using ANCOVA. s and ns: slopes (or ordinates) of both cohorts are significantly different or not at the $5 \%$ level

\begin{tabular}{|c|c|c|c|c|c|c|c|c|}
\hline Ingestion & & CI & CII & CIII & CIV & $\mathrm{CV}$ & Female & ANOVA \\
\hline \multirow[t]{2}{*}{$\mathrm{C}$} & Cohort L & $1.2 \pm 0.1$ & $2.1 \pm 0.1$ & $5.1 \pm 0.8$ & $11.4 \pm 4.1$ & $17.0 \pm 2.3$ & $22.7 \pm 2.3$ & \multirow{3}{*}{$\begin{array}{c}\mathrm{p}<0.000 \\
\mathrm{CI}<\mathrm{CII}<\mathrm{CIII}<\mathrm{CIV}<\mathrm{CV}-\mathrm{F} \\
\mathrm{p}<0.000 \\
\mathrm{CI}-\mathrm{CII}<\mathrm{CIII}<\mathrm{CIV}-\mathrm{CV}<\mathrm{F}\end{array}$} \\
\hline & Cohort H & $3.9 \pm 0.4$ & $6.0 \pm 1.2$ & $11.6 \pm 3.2$ & $32.5 \pm 4.8$ & $26.6 \pm 9.2$ & $54.3 \pm 8.3$ & \\
\hline ANCOVA & $\begin{array}{l}\text { Slopes } \\
\text { Ordinates }\end{array}$ & \multicolumn{6}{|c|}{$\begin{array}{l}\longrightarrow \text { ns } p=0.06 \\
\text { s } \quad p=0.001\end{array}$} & \\
\hline \multirow[t]{2}{*}{$\mathrm{N}$} & Cohort L & $0.2 \pm 0.0$ & $0.3 \pm 0.0$ & $0.7 \pm 0.1$ & $1.6 \pm 0.6$ & $2.3 \pm 0.3$ & $3.1 \pm 0.3$ & \multirow{3}{*}{$\begin{aligned} \mathrm{p}<0.000 \\
\mathrm{CI}<\mathrm{CII}<\mathrm{CIII}<\mathrm{CIV}<\mathrm{CV}-\mathrm{F} \\
\mathrm{p}<0.000 \\
\mathrm{CI}-\mathrm{CII}<\mathrm{CIII}<\mathrm{CIV}-\mathrm{CV}<\mathrm{F}\end{aligned}$} \\
\hline & Cohort H & $0.5 \pm 0.1$ & $0.8 \pm 0.2$ & $1.6 \pm 0.4$ & $4.4 \pm 0.7$ & $3.6 \pm 1.3$ & $7.4 \pm 1.1$ & \\
\hline ANCOVA & $\begin{array}{l}\text { Slopes } \\
\text { Ordinates }\end{array}$ & 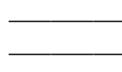 & 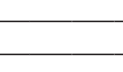 & - ns p & $\begin{array}{l}0.06- \\
0.001-\end{array}$ & & & \\
\hline
\end{tabular}




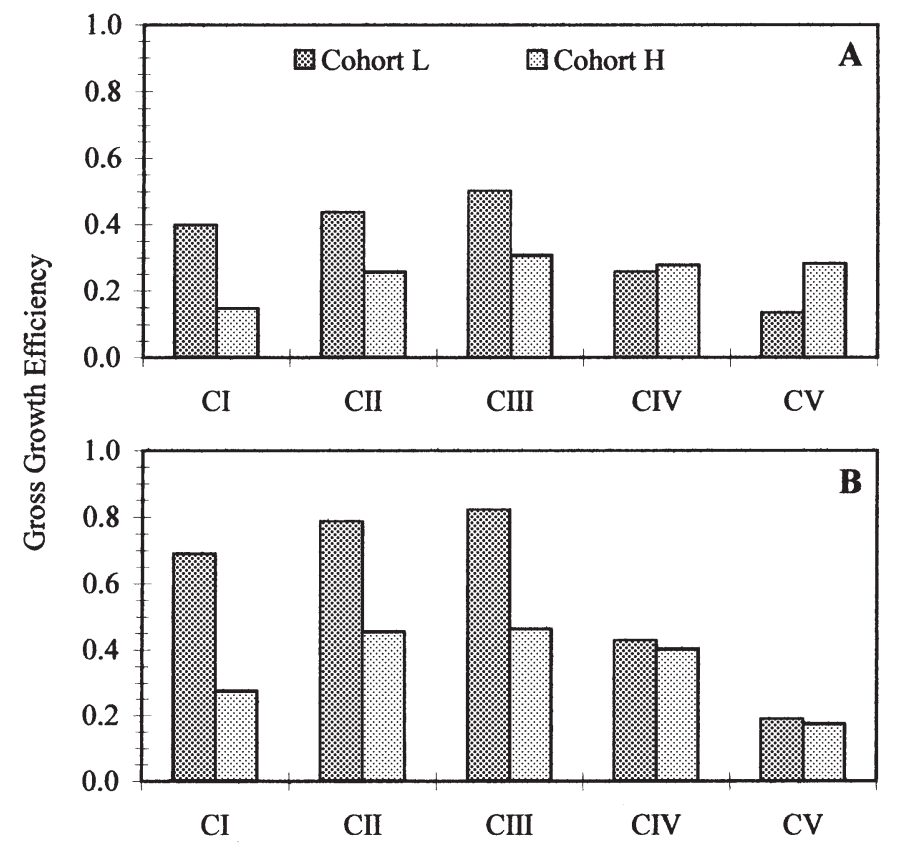

Fig. 6. Calanus helgolandicus. Gross growth efficiency of copepodite Stages CI to CV of Cohorts L and $\mathrm{H}$ expressed in terms of (A) carbon or (B) nitrogen. The growth rates found with Method II were used to calculate gross growth efficiency

synthesis during these stages. This phenomenon was masked with Method I, especially in the results for CV, where higher growth rates were found in terms of nitrogen than of carbon (when the opposite is expected because of a high lipid deposition at this stage). Third, growth rates for Stage CV in terms of carbon were rather similar in both cohorts with Method I $\left(0.041 \mathrm{~d}^{-1}\right.$ for Cohort L and $0.035 \mathrm{~d}^{-1}$ for Cohort $\mathrm{H}$ ), whereas rates were markedly different with Method II $\left(0.063 \mathrm{~d}^{-1}\right.$ for Cohort L and $0.115 \mathrm{~d}^{-1}$ for Cohort $\mathrm{H}$ ), which means that the effect of food supply on growth was only apparent with Method II. Method I tends to underestimate the growth rate of $\mathrm{CV}$ because the growth of the female (somatic plus reproductive growth, i.e. due, in the latter case, to gonad and egg formation) is much lower than for CV. In other words, the more the growth rates of 2 successive stages differ, the more inaccurate is Method I.

The importance of food concentration for explaining variability in production in the field has been discussed for some time (Mayzaud \& Poulet 1978, McLaren \& Corkett 1978). Some authors argue that the importance of this factor in situ is masked since the weaker individuals, which have grown slowly, are eliminated from the population because of higher mortality rates (natural or due to predation; Lopez 1991, Carlotti \& Nival 1992b). However, the use of an unsuitable method to calculate the growth rate, especially for $\mathrm{CV}$, can also mask the influence of food quantity in the field, principally in the case of large copepod species known for their substantial lipid synthesis at this stage. One could say that these methodological aspects can be neglected because the main differences between both methods are mainly found for 1 stage, namely CV. However, when comparing the production of each stage, that of $\mathrm{CV}$ is usually most important; this is why in some studies, production is estimated only by considering Stages CIV and CV (Peterson et al. 1991, Peterson \& Hutchings 1995). In such cases, the use of an accurate method to estimate the CV growth rate becomes particularly significant.

In the case of an asynchronous cohort, the animal's ages are relatively evenly distributed within the stage, and the animals that are sampled for estimating weight provide a rather adequate value of the mean weight. However, even though Method I might be convenient for estimating growth rates in the field, there is still the problem that, in Eq. (1), the growth rate of Stage $i$ found with this method is dependent not only on the characteristics of Stage I but is also the result of mean weights $W_{i}$ and $W_{i+1}$ and of the duration $D_{i}$ (see 'Materials and methods'). For this reason, McLaren \& Leonard (1995) suggested that it was better to use the duration between the mid-stage $i$ and $i+1$ since it was in fact the adequate duration during which the weight increment occurred (see also Escribano \& McLaren 1999). For Stage CV, McLaren \& Leonard (1995) assumed that $D_{i}$ is half the duration of Stage CV, since they neglected the growth of the female. If we apply this change to the $\mathrm{CV}$ in our data, we obtain growth rates twice those found with Method I, but still the influence of food concentration is not apparent in the results.

Using Method II on field data is limited to copepod populations with a recruitment period short enough to follow the development of the cohort throughout the successive stage (synchronous cohort); this is true for a number of large calanoid copepods. However, when this condition is encountered, the use of Method II is also limited by the high number of samples required to follow the weight increase within a stage. Shreeve \& Ward (1998) proposed a method to calculate the growth rates for large calanoids that is similar to our Method II since they considered in Eq. (1) the initial weights of the 2 successive stages. In their study, the authors estimated the initial weight by considering that it was equal to the weight of newly moulted individuals. However, the method by Shreeve \& Ward (1998) does not provide a good estimate for the growth rate of the $\mathrm{CV}$ since it does not consider the final weight of the $\mathrm{CV}$ but the initial weight of the female. It is also important to keep in mind that Method II tends 
to provide growth rates in the upper range of those of all the cohort individuals since they characterize the first $50 \%$ of the individuals ahead of the cohort development.

\section{Effects of the food level on the cohort}

In agreement with the findings of a number of authors (Vidal 1980, Diel \& Klein Breteler 1986, Escribano et al. 1997, Hygum et al. 2000), the development time of the first 3 copepodite stages was not affected by food level; however, the 2 last stages were. This indicates that the concentration below which development is limited by food varies with stage and is higher for the oldest copepodites. Food concentration also influenced the length, the total and structural weight and the growth rates of all copepodite stages, as was found by Escribano \& McLaren (1992) (but structural weight was not dependent on the food quantity in their study) and by Escribano et al. (1997). As expected (Vidal 1980, Diel \& Klein Breteler 1986), the food concentration below which growth is limited (called the 'critical concentration', Cc) is higher than the one limiting development since the food level did not influence the durations of the first 3 stages. Moreover, Richardson \& Verheye (1999) showed that the Cc for growth varied with stage; the older the stage, the higher the Cc. In general terms, these authors established a positive relationship between $\mathrm{Cc}$ and copepod size (i.e. the size of different developmental stages or species; see also Hirst \& Lampitt 1998, Hopcroft et al. 1998b). Such a phenomenon explains why in our experiments the effect of food quantity becomes more pronounced with stage.

The high food concentration that we used represented excess food since our estimates of stage duration were similar to those found by Thompson (1982) for Calanus helgolandicus and/or C. finmarchicus held individually at excess food at $14.5^{\circ} \mathrm{C}$, and to those estimated using the Belehrádek function established by Corkett et al. (1986). Our low concentration appears to be close to the limiting food concentrations encountered in the field since our estimates of length and weight correspond to the lower range of the values reported by Bottrell \& Robins (1984) on field animals sampled in summer (temperature $\sim 15^{\circ} \mathrm{C}$ ) in the Celtic Sea. Some of the CIV, CV and adults of C. helgolandicus collected off Plymouth at a similar temperature were even smaller and lighter than those from our Cohort L (unpubl. data). In the field, the individual variability is high, probably because individuals from 1 population can encounter very different food concentrations due to a patchy distribution of the food (Båmstedt 1988).
Our study shows an increase in female weight during the first $10 \mathrm{~d}$ of adult life (particularly for the females of Cohort L, Fig. 3). This increase is certainly due to an increase in feeding activity to complete gonad maturation (Rey et al. 1999). This initial growth of the female is not expected to occur in every copepod species. It is more common to find a drop in female weight after moulting (as, in fact, also occurred with our females but only after the first $10 \mathrm{~d}$, see Rey-Rassat et al. 2002, this volume). This drop in female weight occurs particularly in large copepod species with lipid reserves, which build eggs from internal resources (Evanson et al. 2000). Moreover, the period during which females have a positive growth must vary with species. For those which have a relatively long adult lifetime (e.g. Calanus), the weight increment is certainly more apparent since it occurs over a longer period than for those which have a shorter lifetime (e.g. Centropages).

Interesting results were found for the sex ratio of both cohorts. As found by Hygum et al. (2000) for Calanus finmarchicus, the percentage of males was higher in the cohort reared at the highest food concentration. Such results have been further analyzed by Irigoien et al. (2000) who suggested that the sex determination is not strictly genetic, but depends on the copepodite growth rate.

In our study, we were able to estimate the influence of food quantity on the GGE. Interestingly, in Cohort $\mathrm{H}$, GGE remains around $30 \%$ throughout the copepodite stages, which is a common value in the literature (Kiørboe et al. 1985, Straile 1997). In other words, each copepodite stage of Cohort $\mathrm{H}$ would invest the same amount of food ingested in relation to their respective weight, for their growth. This is not the case in Cohort L, where the GGE is higher for copepodites CI to CIII, and there are important differences between stages. These results indicate that at low food concentrations early copepodites can somehow adjust their metabolism to reduce the consequences of food limitation, whereas this ability seems to be reduced in Stages CIV and CV. It is possible that the accumulation of lipids and gonad maturation are more constraining processes where resources cannot be allocated to different pools to improve GGE. Our values of GGE for Cohort L are higher than those found by Paffenhöfer (1976) on Calanus pacificus (food level $40 \mu \mathrm{g} \mathrm{C}^{-1}$ ) in Stages CI, CII and CIII but fit quite well in the case of Stages CIV and CV.

\section{Moulting processes}

One of the benefits of the intensive sampling in our study is that we were able to characterize the weight 
increment within a stage in order to better appreciate the internal dynamics of the species. Carlotti et al. (1993) proposed (through a conceptual model) that at excess food, animals moult when reaching a critical structural weight, which depends on the temperature. According to our results, it is clear that this is also dependent on the food conditions (see also Shreeve \& Ward 1998). We have used our data to determine an index that could indicate the position of an individual within the moulting cycle of its stage (governed through hormonal processes, Skinner 1985) and which would be independent of the origin of the animals. Miller et al. (1990) have proposed a similar approach using the tooth formation of 2 calanoid copepods, 'tooth-stages', that can be used to determine the position of an individual within its development in 1 stage.

On the basis of the model proposed by Carlotti et al. (1993), we can imagine that moulting is activated once a certain threshold concentration of a molecule (e.g. protein since it is known to be a determinant in growth processes) is reached. This threshold level in protein would be a function of the feeding history of the individuals, and therefore, of their size characteristics. The condition factor $(\mathrm{CF})$, which is the ratio of the carbon or nitrogen weight to the cubic length of a particular

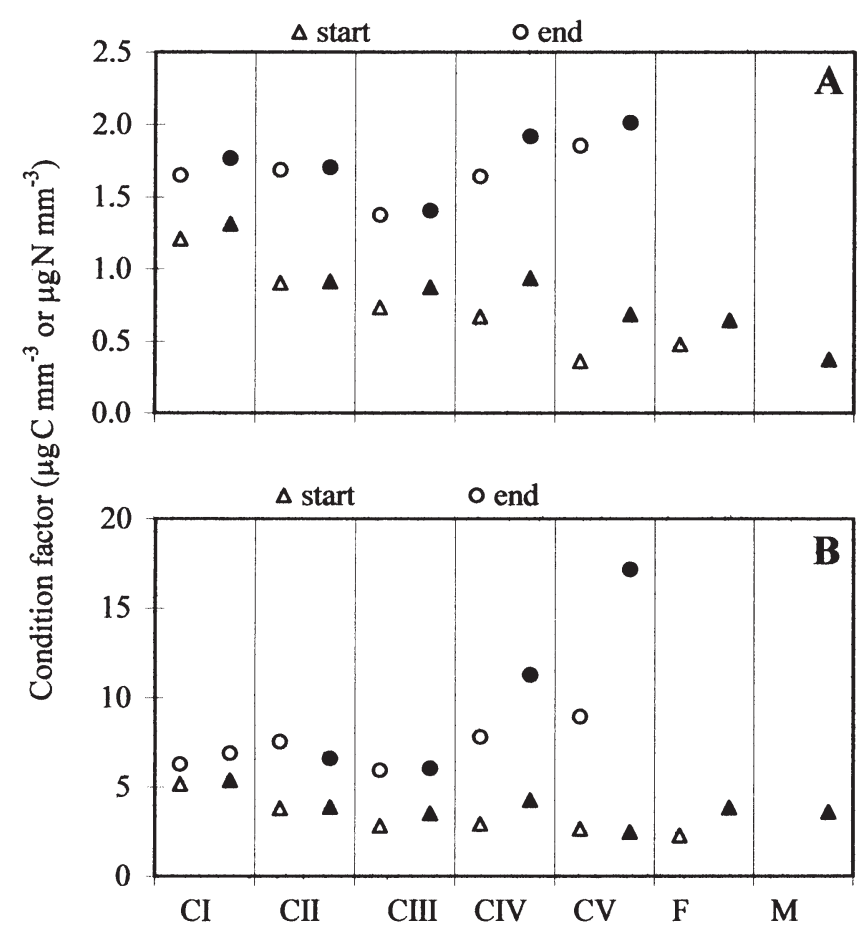

Fig. 7. Calanus helgolandicus. Condition factor $\left(\mathrm{CF}=W / L^{3}\right.$, originally defined by Durbin \& Durbin 1978; $W$ : weight in $\mu g$, $L$ : length in $\mathrm{mm}$ ) of each copepodite stage of Cohorts $\mathrm{L}$ (open symbols) and $\mathrm{H}$ (filled symbols), calculated by considering weight (A) in nitrogen or (B) in carbon obtained at the beginning (triangles) and at the end (circles) of each stage stage (Durbin \& Durbin 1978), could be used as an index to represent this phenomenon. In Fig. 7, we have considered values of the CF calculated using the minimum weight (at the beginning of the stage) and the maximal one (at the end of the stage). We observed a strong increase of the CF between the beginning and the end of a stage. Interestingly, when the CF is estimated from the nitrogen weight $\left(\mathrm{CF}_{\mathrm{N}}\right)$, the initial or final values are relatively similar in both cohorts.

Results found by Campbell et al. (2001) suggest that $\mathrm{CF}_{\mathrm{N}}$ is dependent on food concentration but not on temperature. However, these authors did not distinguish initial and final $\mathrm{CF}_{\mathrm{N}}$ values, which means that their mean value of the $\mathrm{CF}_{\mathrm{N}}$ estimated for Stage $\mathrm{CV}$ at each food concentration may have been influenced by the fact that individuals were not sampled equally during the whole stage duration. By assuming that environmental conditions do not greatly influence the $\mathrm{CF}_{\mathrm{N}}$, $\mathrm{CF}_{\mathrm{N}}$ measured on in situ Calanus helgolandicus can be compared to values that we found; this enables the position of the wild individuals within their stage to be determined. For instance, it could be very helpful to know whether the weight of a stage estimated from in situ individuals is an adequate value of its mean weight (in the case of an asynchronous cohort; the value of $\mathrm{CF}_{\mathrm{N}}$ is an intermediate between the minimum and maximum values that we found for this stage in our experiments) or whether it is a biased value (in the case of a synchronous cohort; the value of $\mathrm{CF}_{\mathrm{N}}$ is close to our minimum, i.e. individuals that enter the stage, or close to our maximum, i.e. individuals that will leave the stage soon). Hence, when the mean weight of wild individuals appears to be biased, the estimate of the growth rate with Method I has to be considered with caution (Rey-Rassat et al. unpubl.).

\section{CONCLUSION}

This study provides detailed information on physiological parameters of 2 cohorts reared at different food levels, enabling us to test the impact of food concentration on these parameters: (1) Development times were not synchronous and were affected by the food concentration for Stages CIV and CV but not for the younger stages. Our results suggest that the food concentration below which the growth is limited (called the 'critical concentration', $\mathrm{Cc}_{\mathrm{c}}$ ) is higher than that limiting development. (2) Differences between weight (or body size) of individuals from both cohorts increased with stage, mostly because of a much more pronounced lipid accumulation at high food concentration. (3) Growth rates were better described using a new method based on the initial weight of each stage. This method enabled the influence of food concentra- 
tion on growth and lipid accumulation through stages to be demonstrated. Females after moulting were characterized by a low growth. (4) While GGE remained around $30 \%$ through the copepodite stages in Cohort $\mathrm{H}$, it varied strongly in Cohort L. At low food concentrations, early copepodites can somehow adjust their metabolism to reduce the consequences of food limitation, whereas this ability seems to be reduced in Stages CIV and CV. And finally (5) an index used to indicate the position of an individual within its stage is proposed. Its value is independent of feeding history of the individual and is calculated from length and weight measurements. Such an index could be useful to establish the status of CVs sampled in the field.

Acknowledgements. This study was carried out as part of the Trans-Atlantic Study of Calanus finmarchicus project (TASC) and was supported financially by the Commission of the European Community through contract MAS3-CT95-0039 (TASC) and the Plymouth Marine Laboratory. We thank J. Shepherd, Plymouth Marine Laboratory, for support with the rearing of cohorts.

\section{LITERATURE CITED}

Båmstedt U (1988) Ecological significance of individual variability in copepod bioenergetics. Hydrobiologia 167-168: 43-59

Bottrell HH, Robins DB (1984) Seasonal variations in length, dry weight, carbon and nitrogen of Calanus helgolandicus from the Celtic Sea. Mar Ecol Prog Ser 14:259-268

Burkill PH, Kendall TF (1982) Production of the copepod Eurytemora affinis in the Bristol Channel. Mar Ecol Prog Ser $7: 21-31$

Calbet A, Trepat I, Arin L (2000) Naupliar growth versus egg production in the calanoid copepod Centropages typicus. J Plankton Res 22(7):1393-1402

Campbell RG, Wagner MM, Teegarden GJ, Boudreau CA, Durbin EG (2001) Growth and development rates of the copepod Calanus finmarchicus reared in the laboratory. Mar Ecol Prog Ser 221:117-124

Carlotti F, Nival P (1992a) Model of copepod growth and development: moulting and mortality in relation to physiological processes during an individual moult cycle. Mar Ecol Prog Ser 84:219-233

Carlotti F, Nival S (1992b) Moulting and mortality rates of copepods related to age within stage: experimental results. Mar Ecol Prog Ser 84:235-243

Carlotti F, Sciandra A (1989) Population dynamics model of Euterpina acutifrons (Copepoda: Harpacticoida) coupling individual growth and larval development. Mar Ecol Prog Ser 56:225-242

Carlotti F, Krause M, Radach G (1993) Growth and development of Calanus finmarchicus related to the influence of temperature: experimental results and conceptual model. Limnol Oceanogr 38(6):1125-1134

Corkett CJ (1984) Observations on development in copepods. Studies on Copepoda II. Proc 1st Int Conf Copepoda, Amsterdam, 1981. Crustaceana Suppl 7:150-153

Corkett CJ, McLaren IA, Sévigny JM (1986) The rearing of marine copepods Calanus finmarchicus (Gunnerus), $C$. glacialis Jaschnov and C. hyperboreus Kroyer with com- ment on the equiproportional rule (Copepoda). Syllogeus 58:539-546

Diel S, Klein Breteler WCM (1986) Growth and development of Calanus spp. (Copepoda) during spring phytoplankton succession in the North Sea. Mar Biol 91:85-92

Durbin EG, Durbin AG (1978) Length and weight relationships of Acartia clausi from Narragansett Bay, RI. Limnol Oceanogr 23:958-969

Escribano R, McLaren IA (1992) Influence of food and temperature on lengths and weights of two marine copepods. J Exp Mar Biol Ecol 159:77-88

Escribano R, McLaren IA (1999) Production of Calanus chilensis in the upwelling area of Antofagasta, northern Chile. Mar Ecol Prog Ser 177:147-156

Escribano R, Irribarren C, Rodriguez L (1997) Influence of food quantity and temperature on development and growth of the marine copepod Calanus chilensis from northern Chile. Mar Biol 128:281-288

Evanson M, Bornhold EA, Goldblatt RH, Harrison PJ, Lewis A (2000) Temporal variation in body composition and lipid storage of the overwintering, subarctic copepod Neocalanus plumchrus in the Strait of Georgia, British Columbia (Canada). Mar Ecol Prog Ser 192:239-247

Frost BW (1972) Effects of size and concentration of food particles on the feeding behavior of the marine planktonic copepod Calanus pacificus. Limnol Oceanogr 17(6): 805-815

Fryd M, Haslund OH, Wohlgemuth O (1991) Development, growth and egg production of the two copepod species Centropages hamatus and Centropages typicus in the laboratory. J Plankton Res 13:683-689

Guillard RRL (1975) Culture of phytoplankton for feeding marine invertebrates. In: Smith WL, Chaney MH (eds) Culture of marine invertebrate animals. Plenum Publishing, New York, p 29-60

Harris R, Paffenhöfer GA (1976) Feeding, growth and reproduction of the marine planktonic copepod Temora longicornis Müller. J Mar Biol Assoc UK 56:675-690

Hirst AG, Lampitt RS (1998) Towards a global model in situ weight-specific growth in marine planktonic copepods. Mar Biol 132:247-257

Hirst AG, McKinnon AD (2002) Does egg production represent adult female copepod growth? A call to account for body weight changes. Mar Ecol Prog Ser 223:179-199

Hopcroft RR, Roff JC, Lombard D (1998a) Production of tropical copepods in Kingston Harbour, Jamaica: the importance of small species. Mar Biol 130:593-604

Hopcroft RR, Roff JC, Webber MK, Witt JDS (1998b) Zooplankton growth rates: the influence of size and resources in tropical marine copepodites. Mar Biol 132:67-77

Huntley ME, Lopez MDG (1992) Temperature-dependent production of marine copepods: a global synthesis. Am Nat 140(2):201-242

Hygum BH, Rey C, Hansen BW, Tande K (2000) Importance of food quantity to structural growth rate and neutral lipid reserves accumulated in Calanus finmarchicus (Gunnerus). Mar Biol 136:1057-1074

Irigoien X, Obermüller B, Head RN, Harris RP, Rey C, Hansen BW, Hygum BH, Durbin EG (2000) On the sex ratio determination of Calanus. ICES J Mar Sci 57:1752-1763

Jellison R, Dana GL, Melack JM (1995) Zooplankton cohort analysis using systems identification techniques. J Plankton Res 17(11):2093-2115

Kimmerer WL, McKinnon AD (1987) Growth, mortality, and secondary production of the copepod Acartia tranteri in Westernport Bay, Australia. Limnol Oceanogr 32(1):14-28

Kiørboe T, Mohlenberg F, Riisgard HU (1985) In situ feeding 
rates of planktonic copepods: A comparison of four methods. J Exp Mar Biol Ecol 88:67-81

Klein Breteler WCM, Fransz HG, Gonzalez SR (1982) Growth and development of four calanoid copepod species under experimental and natural conditions. Neth J Sea Res 16: 195-207

Klein Breteler WCM, Schogt N, Van der Meer J (1994) The duration of copepod life stages estimated from stagefrequency data. J Plankton Res 16:1039-1057

Landry MR (1983) The development of marine calanoid copepods with comment on the isochronal rule. Limnol Oceanogr 28:614-624

Lopez MD (1991) Moulting and mortality depend on age and stage in naupliar Calanus pacificus: implication for development time of field cohorts. Mar Ecol Prog Ser 75:79-89

Mayzaud P, Poulet SA (1978) The importance of the time factor in the response of zooplankton to varying concentrations naturally occurring particulate matter. Limnol Oceanogr 23:1144-1154

McKinnon AD (1996) Growth and development in the subtropical copepod Acrocalanus gibber. Limnol Oceanogr 41:1438-1447

McLaren IA, Corkett CJ (1978) Unusual genetic variation in body size, development times, oil storage and survivorship in the marine copepod Pseudocalanus. Biol Bull 155: 347-359

McLaren IA, Leonard A (1995) Assessing the equivalence of growth and egg production of copepods. ICES J Mar Sci 52:397-408

McLaren IA, Tremblay MJ, Corkett CJ, Roff JC (1989) Copepod production on the Scotian Shelf based on life-history analyses and laboratory rearings. Can J Fish Aquat Sci 46: 560-583

Miller CB, Tande K (1993) Stage duration estimation for Calanus populations, a modelling study. Mar Ecol Prog Ser 102:15-34

Miller CB, Huntley ME, Brooks ER (1984) Post-collection molting rates of planktonic, marine copepods: measurement, applications, problems. Limnol Oceanogr 29(6):1274-1289

Miller CB, Nelson DM, Weiss C, Soeldner AH (1990) Morphogenesis of opal teeth in calanoid copepods. Mar Biol 106: 91-101

Miller CB, Morgan CA, Prahl FG, Sparrow MA (1998) Storage lipids of the copepod Calanus finmarchicus from Georges Bank and the Gulf of Maine. Limnol Oceanogr 43(3): 488-497

Paffenhöfer GA (1976) Feeding, growth, and food conversion of the marine planktonic copepod Calanus helgolandicus. Limnol Oceanogr 21(1):39-50

Peterson WT, Hutchings L (1995) Distribution, abundance and production of the copepod Calanus agulhensis on the Agulhas Bank in relation to spatial variations in hydro-

Editorial responsibility: Otto Kinne (Editor), Oldendorf/Luhe, Germany graphy and chlorophyll concentration. J Plankton Res 17(12):2275-2294

Peterson WT, Painting SJ (1990) Developmental rates of the copepods Calanus australis and Calanoides carinatus in the laboratory, with discussion of methods used for calculation of development time. J Plankton Res 12(2):283-293

Peterson WT, Tiselius P, Kiørboe T (1991) Copepod egg production, moulting and growth rates, and secondary production, in the Skagerrak in August 1988. J Plankton Res 13(1):131-154

Rey C, Carlotti F, Tande K, Hygum BH (1999) Egg and faecal pellet production of Calanus finmarchicus females from controlled mesocosms and in situ populations: influence of age and feeding history. Mar Ecol Prog Ser 188:133-148

Rey C, Harris R, Irigoien X, Head R, Carlotti F (2001) Influence of algal diet on growth and ingestion of Calanus helgolandicus nauplii. Mar Ecol Prog Ser 216:151-165

Rey-Rassat C, Irigoien X, Harris R, Head R, Carlotti F (2002) Egg production rates of Calanus helgolandicus females reared in the laboratory: variability due to present and past feeding conditions. Mar Ecol Prog Ser 238:139-151

Richardson J, Verheye HM (1998) The relative importance of food and temperature to copepod egg production and somatic growth in the southern Benguela. J Plankton Res 20(12):2379-2399

Richardson J, Verheye HM (1999) Growth rates of copepods in the southern Benguela upwelling system: the interplay between body size and food. Limnol Oceanogr 44(2): 382-392

Sargent JR, Henderson RJ (1986) Lipids. In: Corner ED, O'Hara SCM (eds) The biological chemistry of marine copepods. Clarendon Press, Oxford, p 59-108

Shreeve RS, Ward P (1998) Moulting and growth of the early stages of two species of Antarctic calanoid copepod in relation to differences in food supply. Mar Ecol Prog Ser 175:109-119

Shreeve RS, Ward P, Murray AWA (1998) Moulting rates of Calanus helgolandicus: an inter-comparison of experimental methods. J Exp Mar Biol Ecol 224:145-154

Skinner DM (1985) Interacting factors in the control of the crustacean molt cycle. Am Zool 25:275-284

Straile D (1997) Gross growth efficiencies of protozoan and metazoan zooplankton and their dependence on food concentration, predator-prey weight ratio, and taxonomic group. Limnol Oceanogr 42(6):1375-1385

Thompson BM (1982) Growth and development of Pseudocalanus elongatus and Calanus sp. in the laboratory. J Mar Biol Assoc UK 62:359-372

Vidal J (1980) Physioecology of zooplankton. I. Effects of Phytoplankton concentration, temperature, and body size on the growth rate of Calanus pacificus and Pseudocalanus sp. Mar Biol 56:111-134

Submitted: March 21, 2001; Accepted: February 26, 2002

Proofs received from author(s): July 18, 2002 